\title{
Postoperative awake paralysis in the intensive care unit after cardiac surgery due to residual neuromuscular blockade: a case report and prospective observational study État d'éveil avec paralysie postopératoire en unité de soins
intensifs après chirurgie cardiaque due à un bloc neuromusculaire
résiduel: étude de cas et étude observationnelle prospective
}

\author{
Maxim Roy, MD - Nathalie Morissette, PhD, MDCM - Martin Girard, MD • \\ Nicholas Robillard, MD $\cdot$ Pierre Beaulieu, MD, PhD \\ Received: 29 November 2015/Revised: 21 December 2015/ Accepted: 28 January 2016/Published online: 2 March 2016 \\ (C) Canadian Anesthesiologists' Society 2016
}

\begin{abstract}
Purpose We report a case of awake paralysis due to residual neuromuscular blockade (NMB) in the intensive care unit (ICU) in a patient following fast-track cardiac surgery. As a result of this case, we performed a prospective quality assurance audit to investigate the incidence of residual paralysis in the ICU in a similar population of cardiac surgery patients.

Clinical features and audit methods $A$ 73-yr-old woman $(69 \mathrm{~kg})$ underwent coronary artery bypass surgery under anesthesia induced with intravenous sufentanil $25 \mu \mathrm{g}$, midazolam $5 \mathrm{mg}$, ketamine $25 \mathrm{mg}$, and rocuronium $100 \mathrm{mg}$ (followed by two additional 50-mg doses during surgery) and maintained with sevoflurane. Postoperatively in the ICU, the patient was initially sedated with propofol (50 $\mathrm{mg} \cdot \mathrm{hr}^{-1}$ ) but failed to awaken $90 \mathrm{~min}$ after its cessation. As train-of-four neurostimulation showed residual paralysis, she was resedated. Neostigmine $3 \mathrm{mg}$ and glycopyrrolate $0.6 \mathrm{mg}$ were administered, and she was extubated 30 min later. During this episode of residual paralysis, the patient was conscious and reported explicit memory of the events. She was discharged on day 7 without psychological distress related to her postoperative awake paralysis. We
\end{abstract}

M. Roy, MD · M. Girard, MD · P. Beaulieu, MD, PhD ( $\square)$ Department of Anesthesiology, CHUM-Hôtel-Dieu, 3840 rue St-Urbain, Montréal, QC H2W 1T8, Canada

e-mail: pierre.beaulieu@umontreal.ca

N. Morissette, PhD, MDCM - M. Girard, MD .

N. Robillard, MD

Division of Critical Care, Department of Medicine,

CHUM-Hôtel-Dieu, Montréal, QC, Canada subsequently performed a prospective audit in 50 consecutive patients to determine the timing of $N M B$ dosing and to quantify the incidence of residual paralysis after fast-track cardiac surgery.

Results Of the 50 patients studied, 24 (48\%) had received an $N M B$ during the last hour of surgery and 33 (66\%) had evidence of residual paralysis during the immediate postoperative period.

Conclusion Postoperative residual paralysis after fasttrack cardiac surgery was common in our institution and likely contributed to the reported case of postoperative awake paralysis. We suggest that an NMB not be administered after intubation in fast-track patients. If given, however, it must be well communicated to the ICU team upon ICU admission. We further recommend routine assessment of neuromuscular function before sedation is weaned prior to extubation.
Résumé
Objectif Nous décrivons le cas d'un état d 'éveil avec paralysie due à un bloc neuromusculaire (BNM) résiduel en unité de soins intensifs (USI) chez un patient après chirurgie cardiaque à parcours rapide. À la suite de ce cas, nous avons réalisé un contrôle prospectif d'assurance de la qualité de l'acte pour étudier l'incidence de la paralysie résiduelle en USI dans une population comparable de patients ayant subi une chirurgie cardiaque.
Caractéristiques cliniques et méthodes du contrôle Une femme âgée de 73 ans $(69 \mathrm{~kg})$ a subi une chirurgie de pontage coronarien sous anesthésie intraveineuse induite par sufentanil $25 \mu \mathrm{g}$, midazolam $5 \mathrm{mg}$, kétamine $25 \mathrm{mg}$ et rocuronium $100 \mathrm{mg}$ (suivi de deux doses supplémentaires de $50 \mathrm{mg}$ au cours de 
l'intervention) et entretenue par du sévoflurane. En postopératoire, dans l'USI, la sédation de la patiente a été assurée initialement par du propofol $\left(50 \mathrm{mg} \cdot \mathrm{h}^{-1}\right)$, mais la patiente ne s'est pas réveillée 90 minutes après l'arrêt $d u$ propofol. La neurostimulation en train de quatre montrant une paralysie résiduelle, la sédation a été réinstaurée. De la néostigmine $3 \mathrm{mg}$ et du glycopyrrolate $0,6 \mathrm{mg}$ lui ont été administrés; elle a été extubée 30 minutes plus tard. Pendant cet épisode de paralysie résiduelle, la patiente était consciente et a décrit des souvenirs explicites des événements. Elle a reçu son congé au $7^{e}$ jour sans détresse psychologique liée à sa paralysie en état d'éveil postopératoire. Nous avons ensuite mené un contrôle prospectif chez 50 patients consécutifs pour déterminer le moment de l'administration du BNM et pour quantifier l'incidence de la paralysie résiduelle après chirurgie cardiaque à parcours rapide.

Résultats Sur les 50 patients étudiés, 24 (48\%) avait reçu un BNM au cours de la dernière heure de l'intervention chirurgicale et 33 (66\%) avaient des signes de paralysie résiduelle au cours de la période postopératoire immédiate.

Conclusion La paralysie résiduelle postopératoire après chirurgie cardiaque à parcours rapide était fréquente dans notre établissement et a probablement contribué au cas d'état d'éveil avec paralysie postopératoire décrit. Nous suggérons de ne pas administrer de BNM après l'intubation chez les patients à parcours rapide. Néanmoins, si le bloc est administré, il doit y avoir une bonne communication avec l'équipe de l'USI lors de l'admission en USI. Nous recommandons en outre d'évaluer systématiquement la fonction neuromusculaire avant la disparition de la sédation et avant l'extubation.

Cardiac surgery patients have been historically extubated after a prolonged period of intensive care unit (ICU) observation and monitoring. With the development of fasttrack cardiac surgery, patients are now extubated one to six hours after surgery ${ }^{1}$ and sometimes even earlier while still in the operating room. This implies that patients must have little to no residual effect of the anesthetic agents administered during surgery before attempting to wean them from ventilation for extubation. Consequently, optimal care is needed to manage the sedation and neuromuscular blocker (NMB) given to these patients. This is especially true because the liberal use of NMBs during cardiac surgery may result in residual postoperative paralysis. The repetitive administration of large doses of an intermediate-acting NMB, accumulating to four to five times the $\mathrm{ED}_{95}$ can prolong neuromuscular blockade [i.e., train-of-four $(\mathrm{TOF})$ ratio $<0.9]$ for as long as four hours after the last dose. ${ }^{2}$ Moreover, cardiac surgery patients may develop specific conditions during surgery that alter the metabolism and action of these drugs (e.g., hypothermia, hypermagnesemia, renal or hepatic insufficiency), ${ }^{3}$ which could enhance the drug's paralytic effect. Hence, a risk of postoperative residual paralysis is present in this patient population that requires physicians to remain vigilant regarding its occurrence. Such vigilance could prevent medical and psychological complications, such as postoperative awake paralysis.

Here, we present a case of postoperative awake paralysis in the ICU following fast-track cardiac surgery. The paralysis was due to residual neuromuscular blockade during weaning from mechanical ventilation. Written consent was obtained from the patient for this publication.

Following this episode, we undertook a prospective quality assurance audit to determine the timing of $\mathrm{NMB}$ dosing and to quantify the incidence of residual paralysis after fast-track cardiac surgery.

\section{Case report}

A 73-yr-old woman $(69 \mathrm{~kg}$ ) with unstable angina in the preceding five weeks was admitted to hospital to undergo multivessel off-pump coronary artery bypass surgery. She had a past medical history of well-controlled hypertension and dyslipidemia for which she took metoprolol and rosuvastatin. She was also on aspirin, vitamin D, calcium, and iron supplements. Anesthesia was induced at 8:05 a.m. with intravenous administration of $25 \mu \mathrm{g}$ of sufentanil, 5 $\mathrm{mg}$ of midazolam, $25 \mathrm{mg}$ of ketamine, and $100 \mathrm{mg}$ of rocuronium. A second 50-mg dose of rocuronium was given 120 min later. Anesthesia was maintained with inhaled sevoflurane and an intravenous infusion of sufentanil $\left(0.4 \mu \mathrm{g} \cdot \mathrm{kg}^{-1} \cdot \mathrm{hr}^{-1}\right)$. Upon completion of surgery (three hours after induction) and prior to transfer to the ICU, she received another dose of $50 \mathrm{mg}$ of rocuronium.

On arrival to the ICU, she was sedated with a propofol infusion at $50 \mathrm{mg} \cdot \mathrm{hr}^{-1}$. Her initial temperature was $36.4^{\circ} \mathrm{C}$ and she remained normothermic throughout the immediate postoperative period. Oxygenation and ventilation were adequate (as confirmed by arterial and venous blood gas analyses) but she required a norepinephrine infusion (2 $\mu \mathrm{g} \cdot \mathrm{min}^{-1}$ ) for hemodynamic support. There were no immediate postoperative complications. Hypomagnesemia was corrected with magnesium sulfate $2 \mathrm{~g} i v$. Her immediate postoperative creatinine level was 75 $\mu \mathrm{mol} \cdot \mathrm{L}^{-1}$. At one hour $40 \mathrm{~min}$ after ICU arrival, the patient rapidly met our institutional criteria for weaning from mechanical ventilation (i.e., hemodynamic stability with norepinephrine infusion of $<10 \mu \mathrm{g} \cdot \mathrm{min}^{-1}$, chest tube drainage $<50 \mathrm{~mL} \cdot \mathrm{hr}^{-1}$, oxygen saturation $>94 \%$ with $\mathrm{F}_{\mathrm{I}} \mathrm{O}_{2}$ $<0.5$, and temperature $>36.5^{\circ} \mathrm{C}$ ) and the propofol 
infusion was therefore discontinued. Although spontaneous ventilation with pressure support $\left(12 \mathrm{~cm} \mathrm{H}_{2} \mathrm{O}\right)$ and positive end-expiratory pressure $\left(5 \mathrm{~cm} \mathrm{H}_{2} \mathrm{O}\right)$ was noted an hour after the propofol was discontinued (i.e., three hours after the last dose of rocuronium), the patient did not appear to be "awakening" $30 \mathrm{~min}$ later. Evaluation at that time demonstrated an altered level of consciousness (Richmond Agitation-Sedation Scale of -5) with equally reacting pupils and tongue fasciculations but no retraction to peripheral nociceptive stimuli. Visual and TOF neurostimulation $(70 \mathrm{~mA})$ at the ulnar nerve showed a TOF of 1/4. Propofol $50 \mathrm{mg}$ was immediately given and an infusion restarted. The patient was also given neostigmine $3.0 \mathrm{mg}$ and glycopyrrolate $0.6 \mathrm{mg}$ and was eventually extubated 30 min later after having confirmed a 4/4 TOF response (without tactile fade).

On the following day, the patient reported to the medical team that she remembered everything concerning the event, stating that she felt as if she were a "prisoner of her own body." She remained in the ICU for three days without medical or immediate psychological complications. Her hospitalization was uneventful she was discharged home on postoperative day seven. She did not suffer from any psychological distress related to the episode of awareness at the time of discharge from hospital or at a two-month follow-up visit.

\section{Audit methods}

Following this event, and with Institutional Ethics Committee approval (October 2015), we undertook a prospective observational quality assurance audit at our institution to quantify the incidence of residual NMB within the first $30 \mathrm{~min}$ of admission to the ICU after fasttrack cardiac surgery.

We evaluated 50 consecutive patients, from October 14 to November 20, 2015, who were scheduled for early extubation after cardiac surgery. The exclusion criteria were patients not scheduled for fast-track surgery and those admitted to the ICU from an anesthesiologist (PB) involved in the study. A single investigator assessed all patients during the first $30 \mathrm{~min}$ after their admission to the ICU using a 70 $\mathrm{mA}$ visual and tactile evaluation of TOF stimulation at the ulnar nerve (i.e., assessing adductor pollicis function). The timing of the last administered dose of rocuronium was obtained from the anesthesia chart. We also recorded the type and dose of sedation administered by the ICU team. Finally, we determined whether the anesthesiologist provided any information on the patient's neuromuscular function during the ICU handover process. Because the investigator collecting the audit data was not present during the handovers, this information was collected by subsequent interrogation of the medical and nursing teams. To avoid bias, the cardiac anesthesiologists involved in the care of these patients were not made aware of the study.

\section{Results}

Among the 50 patients evaluated, $33(66 \%)$ had evidence for residual neuromuscular blockade, defined by a TOF of $\leq 4 / 4$ with fade, during the immediate $(<30 \mathrm{~min})$ postoperative period. Among them, $15(30 \%)$ had a TOF of $0 / 4$ (Table 1$)$. During the ICU handover, five anesthesiologists (10\%) mentioned the neuromuscular status of their patient to the ICU team. In all, 24 (48\%) patients received a NMB during the last hour of surgery just prior to the transfer. In $13(26 \%)$ of them, it was much as $50 \mathrm{mg}$ of rocuronium (Table 2). Only one $(2 \%)$ patient in our study received reversal agents before transfer to the ICU. The sedation initially given to patients in the ICU consisted exclusively of propofol infusions at $50-100 \mathrm{mg} \cdot \mathrm{hr}^{-1}$.

\section{Discussion}

This case depicts an incident of postoperative awake paralysis secondary to residual neuromuscular blockade and lack of adequate sedation in the ICU following fasttrack cardiac surgery. Several factors were implicated. First, the anesthesiologist gave a large dose $\left(0.7 \mathrm{mg} \cdot \mathrm{kg}^{-1}\right)$

Table 1 Tactile train-of-four (TOF) during the first $30 \mathrm{~min}$ after admission to the intensive care unit

\begin{tabular}{lc}
\hline Tactile TOF & Number of patients $(\%)$ \\
\hline $0 / 4$ & $15(30 \%)$ \\
$1 / 4$ & $5(10 \%)$ \\
$2 / 4$ & $3(6 \%)$ \\
$3 / 4$ & $0(0 \%)$ \\
$4 / 4$ with fade & $10(20 \%)$ \\
$4 / 4$ without fade & $17(34 \%)$ \\
\hline
\end{tabular}

Table 2 Doses of rocuronium administered during the last hour of cardiac surgery

\begin{tabular}{lc}
\hline Doses of rocuronium $(\mathrm{mg})$ & Number of patients $(\%)$ \\
\hline 0 & $26(52 \%)$ \\
10 & $1(2 \%)$ \\
20 & $4(8 \%)$ \\
30 & $6(12 \%)$ \\
40 & $0(0 \%)$ \\
50 & $13(26 \%)$ \\
\hline
\end{tabular}


of rocuronium to the patient at the end of surgery without communicating this information to the ICU team. Second, the patient also received magnesium supplementation early in the ICU, which is known to prolong neuromuscular blockade. $^{4,5}$ Finally, the criteria for weaning from mechanical ventilation in our institution do not include neuromuscular blockade assessment and reversal.

Residual paralysis because of an NMB is a well-known problem and was first described by Gray in $1948 .^{6}$ Even after major improvements in neuromuscular management and the use of shorter-acting drugs, it is still a problem in the postanesthesia care unit (PACU), with residual NMB effects reported to occur in almost $65 \%$ of patients. ${ }^{7}$ Our results suggest that residual paralysis is also a prevalent problem in fast-track cardiac surgery patients. In our institution, cardiac surgery patients are usually extubated within one to four hours after ICU admission. The results of our quality assurance study raise the concern that some patients may have residual paralysis just prior to the extubation.

In the 5th National Audit Project of the Royal College of Anaesthetists and the Association of Anaesthetists of Great Britain and Ireland concerning accidental awareness during general anesthesia, $23 \%$ of the episodes occurred after surgery but before full recovery. ${ }^{8}$ Factors increasing the risk of accidental awareness in that audit included female sex, age (younger adults but not children), obesity, anesthesiologist seniority (junior trainees), previous awareness, out-of-hours operations, emergencies, type of surgery (obstetric, cardiac, thoracic), and use of an NMB. ${ }^{9}$ It was associated with the potential for psychological sequelae, including post-traumatic stress disorder (PTSD). As many as $43 \%$ of patients who experienced anesthesia awareness while under general anesthesia developed PTSD that had a significant impact on their quality of life two years after the event. ${ }^{10}$

It is unclear if these data can be extrapolated to ICU patients. However, considering the previously reported cases of PTSD after an ICU stay ${ }^{12}$ and after cardiac surgery, ${ }^{13}$ it could be hypothesized that similar findings might be found when awareness is present. This hypothesis is corroborated by a recent report in which some patients were conscious while still paralyzed when transferred to the ICU after butyrylcholinesterase deficiency was suspected. ${ }^{11}$ In our case, the medical and nursing teams did not ask the patient about possible awake paralysis on the same day of the event. Rather, the following day, the patient spoke spontaneously to a nurse about the event. As a result of this event, an educational program regarding the potential risk of awake paralysis has been disseminated to the anesthesia and ICU staff in our hospital.

A previous study has documented that a TOF ratio $<0.9$ is associated with significant symptoms, such as diplopia and generalized weakness. ${ }^{14}$ These symptoms can be distressing for the patient and may impair the ventilation weaning process. A TOF ratio $<0.9$ also causes partial inhibition of the hypoxic ventilatory drive, ${ }^{15}$ a higher aspiration rate, ${ }^{16}$ and airway collapse. ${ }^{17}$ These adverse respiratory events may lead to hypoxemia and reintubation. ${ }^{18,19}$ In non-cardiac surgery patients, residual paralysis can also delay discharge from the PACU. ${ }^{20}$ All of these risks mitigate the potential costs and health benefits of an early extubation strategy.

The fast-track cardiac surgery literature does not support maintenance of a deep neuromuscular blockade during the entire period of surgery. A single intubating dose of an intermediate-acting NMB at anesthesia induction is sufficient for maintenance of good surgical conditions and is generally not associated with delays in extubation ${ }^{21,22}$ Indeed, Cammu et al. recently compared the efficacy of a single dose versus continuous infusions of cisatracurium for maintaining paralysis. They found no differences in anesthetic requirements, surgical conditions, or venous oxygen saturation between the two groups. ${ }^{23}$ Hence, a similar strategy could minimize the risk of residual paralysis and delayed extubation without impairing initial airway control during fast-track cardiac surgery.

In our ICU, sedation is usually initiated with small doses of hypnotic agents (i.e., propofol), often because of the concerns about hemodynamic instability. Therefore, our initial sedation dose $\left(50 \mathrm{mg} \cdot \mathrm{hr}^{-1}\right)$ in the ICU may have been inadequate to prevent consciousness in a still paralyzed patient, a status that could not be immediately recognized by the ICU team as direct neuromuscular function was not monitored. This point emphasizes the importance of sufficient sedation until neuromuscular function has fully recovered. The data obtained through our quality assurance study demonstrate that the neuromuscular blockade status is largely omitted in the handover from the anesthesia team to the ICU team. This omission can have important consequences, especially considering that the neuromuscular status was rarely monitored in our ICU during the study period. Furthermore, clinical examination has been shown to have low sensitivity and specificity for detecting residual paralysis. $^{24,25}$ Therefore, residual paralysis may be underdiagnosed and may result in postoperative awake paralysis. Murphy et al., in a 2002 national survey, showed that only $28 \%$ of cardiac anesthesiologists routinely monitor the neuromuscular blockade in the operating room, and only $8 \%$ routinely reverse it. ${ }^{26}$

In the cardiac surgery population, many interactions can significantly alter NMB pharmacokinetics. For example, magnesium administration is known to prolong neuromuscular blockade. ${ }^{4}$ Indeed, Pinard et al. demonstrated that an ionized magnesium level $>1.31$ 
$\mathrm{mmol} \cdot \mathrm{L}^{-1}$ was associated with a $35 \mathrm{~min}$ prolongation of the initial block induced by cisatracurium. ${ }^{5}$ As our patient received magnesium shortly after ICU arrival, it might have contributed to her prolonged paralysis. Hypothermia, a common finding during the immediate postoperative period and during off-pump cardiac surgery, is also known to prolong neuromuscular block. Its effect is mainly mediated by altered drug elimination and a direct effect of hypothermia on muscle function. ${ }^{27}$

Our quality improvement study has several limitations. The neuromuscular blockade monitoring consisted of tactile and visual assessment of a TOF stimulation, which detects fade only when the TOF ratio is $<0.4{ }^{28}$ It would have been more precise to use alternative stimulation modes (i.e., double-burst stimulation or sustained tetanus), but it would also have been less representative of our usual clinical practice. Furthermore, this monitoring was performed at arrival to the ICU. The incidence of residual paralysis may have been lower if the assessment had been done before initiating weaning from mechanical ventilation. In addition, the quality improvement study was done in only one center, which limits its external validity. Finally, no clinical outcomes (i.e., awareness) were evaluated in our survey. Despite these limitations, our results are consistent with the literature on the adoption of guidelines, ${ }^{29}$ which indicates that they are not uniformly applied in clinical practice. ${ }^{30}$ This practice may have significant deleterious effects on patient outcomes. Our findings also echo previous work on the transfer of information during patient handover to the ICU where crucial information is often omitted. ${ }^{31}$

\section{Conclusion}

Postoperative residual paralysis (i.e., TOF $<0.9$ ) after fasttrack cardiac surgery was common in our institution and likely contributed to our case of postoperative awake paralysis. It may have wide-ranging consequences, ranging from awake paralysis to other, previously reported respiratory complications. The main causes for this problem likely include the combination of using NMBs while not monitoring for their effect and not incorporating appropriate administration of reversal agents. Readily available solutions can be implemented to mitigate the incidence of postoperative awake paralysis. We suggest that NMBs not be further administered after intubation in fast-track patients. If given, however, that fact must be communicated to the ICU team during the handover process. We further recommend routine assessment of neuromuscular function before sedation is weaned prior to extubation.
Author contributions: Maxim Roy was involved in the acquisition of data and in drafting the article. Nathalie Morissette, Martin Girard, Nicholas Robillard, and Pierre Beaulieu were involved in revising the article. All authors were involved in the analysis and interpretation of data and in the revision process.

Conflicts of interest None declared.

Disclosure None declared.

\section{References}

1. Cheng DC, Karski J, Peniston C, et al. Early tracheal extubation after coronary bypass graft surgery reduces costs and improves resource use. A prospective, randomized, controlled trial. Anesthesiology 1996; 85: 1300-10.

2. Murphy GS, Szokol JW, Marymont JH, et al. Recovery of neuromuscular function after cardiac surgery: pancuronium versus rocuronium. Anesth Analg 2003; 96: 1301-7.

3. Naguib M, Lien CA, Meistelman C, et al. Pharmacology of neuromuscular blocking drugs. In: Miller RD, editor. Miller's Anesthesia, 2-Volume Set. 8th ed. NY: Churchill Livingstone Inc.; 2015. p. 958-94.

4. Rotava P, Cavalcanti IL, Barrucand L, Vane LA, Vercosa $N$. Effects of magnesium sulphate on the pharmacodynamics of rocuronium in patients aged 60 years and older: a randomized trial. Eur J Anaesthesiol 2013; 30: 599-604.

5. Pinard AM, Donati F, Martineau R, Denault AY, Taillefer J, Carrier $M$. Magnesium potentiates neuromuscular blockade with cisatracurium during cardiac surgery. Can J Anesth 2003; 50; $172-8$.

6. Gray TC. D-Tubocurarine chloride. Proc R Soc Med 1948; 41: 559-68.

7. Fortier LP, McKeen D, Turner K, et al. The RECITE study: a Canadian prospective, multicenter study of the incidence and severity of residual neuromuscular blockade. Anesth Analg 2015; 121: 366-72.

8. Pandit JJ, Cook TM, Jonker WR, et al. A national survey of anaesthetists (NAP5 Baseline) to estimate an annual incidence of accidental awareness during general anaesthesia in the UK. Anaesthesia 2013; 68: 343-53.

9. Pandit JJ, Andrade J, Bogod DG, et al. 5th National Audit Project (NAP5) on accidental awareness during general anaesthesia: summary of main findings and risk factors. $\mathrm{Br} \mathrm{J}$ Anaesth 2014; 113: 549-59.

10. Whitlock EL, Rodebaugh TL, Hassett AL, et al. Psychological sequelae of surgery in a prospective cohort of patients from three intraoperative awareness prevention trials. Anesth Analg 2015; 120: 87-95.

11. Thomsen JL, Nielsen CV, Eskildsen KZ, et al. Awareness during emergence from anaesthesia: significance of neuromuscular monitoring in patients with butyrylcholinesterase deficiency. $\mathrm{Br}$ J Anaesth 2015; 115(Suppl 1): i78-88.

12. Caiuby AV, Andreoli PB, Andreoli SB. Post-traumatic disorder in intensive care unit patients. Rev Bras Ter Intensiva 2010; 22: 7784.

13. Porhomayon J, Kolesnikov S, Nader ND. The impact of stress hormones on post-traumatic stress disorders symptoms and memory in cardiac surgery patients. J Cardiovasc Thorac Res 2014; 6: 79-84.

14. Kopman AF, Yee LP, Neuman GG. Relationship of train-of-four fade ratio to clinical signs and symptoms of residual paralysis in awake volunteers. Anesthesiology 1997; 85: 765-71. 
15. Wyon $N$, Joensen H, Yamamoto $Y$, Lindahl SG, Eriksson LI. Carotid body chemoreceptor function is impaired by vecuronium during hypoxia. Anesthesiology 1998; 89: 1471-9.

16. Sundman E, Witt $H$, Olsson $R$, Ekberg $O$, Kuylenstierna $R$, Eriksson $L I$. The incidence and mechanisms of pharyngeal and upper esophageal dysfunction in partially paralyzed humans: pharyngeal videoradiography and simultaneous manometry after atracurium. Anesthesiology 2000; 92: 977-84.

17. Eikermann $M$, Vogt $F M$, Herbstreit $F$, et al. The predisposition to inspiratory upper airway collapse during partial neuromuscular blockade. Am J Respir Crit Care Med 2007; 175: 9-15.

18. Murphy GS, Szokol JW, Marymont JH, Greenberg SB, Avram MJ, Vender JS. Residual neuromuscular blockade and critical respiratory events in the postanesthesia care unit. Anesth Analg 2008; 107: 130-7.

19. Grosse-Sundrup M, Henneman JP, Sandberg WS, et al. Intermediate acting non-depolarizing neuromuscular blocking agents and risk of postoperative respiratory complications: prospective propensity score matched cohort study. BMJ 2012; 345: e6329.

20. Butterly A, Bittner EA, George E, Sandberg WS, Eikermann M, $S c h m i d t U$. Postoperative residual curarization from intermediateacting neuromuscular blocking agents delays recovery room discharge. Br J Anaesth 2010; 105: 304-9.

21. Gueret $G$, Rossignol B, Kiss $G$, et al. Is muscle relaxant necessary for cardiac surgery? Anesth Analg 2004; 99: 1330-3.

22. Сатти G. How rationale is muscle relaxant during cardiac surgery? Acta Anaesthesiol Belg 2007; 58: 7-14.

23. Cатти $G$, Cardinael $S$, Lahousse $S$, et al. Muscle relaxation does not influence venous oxygen saturation during cardiopulmonary bypass. J Clin Anest 2007; 19: 105-9.
24. Cammu G, De Witte J, De Veylder J, et al. Postoperative residual paralysis in outpatients versus inpatients. Anesth Analg 2006; 102: 426-9.

25. Hayes AH, Mirakhur RK, Breslin DS, Reid JE, McCourt KC. Postoperative residual block after intermediate-acting neuromuscular blocking drugs. Anesthesia 2001; 56: 312-8.

26. Murphy GS, Szokol JW, Vender JS, Marymont JH, Avram MJ. The use of neuromuscular blocking drugs in adult cardiac surgery: results of a national postal survey. Anesth Analg 2002; 95: 1534-9.

27. Heier T, Caldwell JE. Impact of hypothermia on the response to neuromuscular blocking drugs. Anesthesiology 2006; 104: 107080.

28. Capron F, Fortier LP, Racine S, Donati F. Tactile fade detection with hand or wrist stimulation using train-of-four, double-burst stimulation, 50-hertz tetanus, 100-hertz tetanus, and acceleromyography. Anesth Analg 2006; 102: 1578-84.

29. Checketts MR, Alladi R, Ferguson $K$, et al. Recommandations for standards of monitoring during anaesthesia and recovery 2015: Association of Anaesthetits of Great Britain and Ireland. Anaesthesia 2016; 71: 85-93.

30. Murphy GS, Brull SJ. Residual neuromuscular block: lessons unlearned. Part I: definitions, incidence, and adverse physiologic effects of residual neuromuscular block. Anesth Analg 2010; 111 : 120-8.

31. Moller TP, Madsen MD, Fuhrmann L, Ostergaard D. Postoperative handover: characteristics and considerations on improvement: a systematic review. Eur J Anaesthesiol 2013; 30: 229-42. 